\title{
Charitable Trusts and Human Research Genetic Databases: The Way Forward?*
}

\author{
ANDREA BOGGIO
}

\begin{abstract}
Human genetic research databases cast a new light on the controversial issue of which uses of the human body are morally permissible. More specifically, banking human tissue raises issues relating to the ownership of the samples that the participants have donated, to the ownership of the data that are derived through processing the donated samples, and to the management arrangements that better balance the interest of genetic research with the protection of participants' rights. Winickoff \& Winickoff suggest that the charitable-trust model is a superior legal arrangement for biobanking compared with private biobanking. This paper critically assesses Winickoff \& Winickoff's claim by highlighting some areas of implementation where such a model could be problematic. The charitable trust is certainly an advantageous arrangement because (1) it favors the separation between control and use of the samples, (2) it provides a procedural mechanism that facilitates the participation donor groups in the biobank management and (3) it mediates the different interests that are affected. On the other hand, the charitable-trust model leaves unresolved several issues - among them the ownership of the sample, the right of withdrawal, access and funding mechanism. I conclude that further theoretical and empirical analysis is required in the area.
\end{abstract}

\section{The Challenges of Genomic Biobanking}

Large collections of human tissues cast a new light on the controversial issue of which uses of the human body are morally permissible. The technical possibilities of automatized data analysis of large collections of DNA samples and their bioinformatics processing have developed dramatically over the last few years and are constantly being improved. The protection of genetic data that is collected in human genetic research databases has consequently emerged as a highly complex ethical issue that urgently needs to be addressed. In its summary of the most pressing issues raised by advances in genetic research, the 2002 Report of WHO's Advisory Committee on Health Research on Genomics and World Health points out that "[ $t]$ he planned development of large-scale genetic . . . databases offers a series of hazards and ethical issues which have not been encountered before", and it then outlines, as possible hazards, the "many ambiguities regarding access and control . . . the potential harm to individuals, groups and communities . . . risks . . . arising from access to genetic information, both by individuals themselves and by third parties." 1 Furthermore, the Report lists access by "health insurance companies, government bodies, or the legal profession and police" as well as "the effect of stigmatizing entire countries or particular groups of individuals, and there are concerns about commercial exploitation without adequate compensation" as pressing ethical issues. ${ }^{2}$ Ethical issues become even more acute when genetic data are combined with information on individuals' health, lifestyle or genealogy. Furthermore, human genetic research databases raise specific issues of ownership of samples that the participants have 
donated, ownership of the data that are derived through processing the donated samples, and of management arrangements that better balance the interest of genetic research with the protection of participants' rights.

In recent years, per-profit companies have been increasingly involved in genetic research and in the creation of large genetic databases. However, commercial biobanking has raised even more substantial questions about the conditions under which genetic databases can be established, kept, and made use of in an ethically acceptable way. To address some of the growing concerns, scholars have proposed arrangements that are alternative to commercial biobanking. In a 2003 paper, David and Richard Winickoff proposed the charitable trust as a model for genomic biobanks superior to commercial biobanking. ${ }^{3}$ This paper critically analyzes Winickoff \& Winickoff's article, concluding that the charitable trust model in itself does not solve many of the open questions. My basic argument is that the charitable trust model provides an interesting governance model, but many of the issues can only be solved at level of rules that are governing the trust rather than in the model itself. The following sections lay out my critique of Winickoff $\&$ Winickoff first by describing their proposal (Section 2) and then by critically assessing and illustrating the critical aspects of their proposal (Section 3). Finally, I present my conclusion and provide some indication for further policy research of biobanks (Section 4).

\section{$2 \quad$ The Charitable Trust Model}

A biobank organized as a charitable trust would be created by a trust agreement under which the participant in the research project (or settler), "formally expresses a wish to transfer his or her property interest in the tissue to the trust." By donating the tissue samples to the biobank, the donor contextually appoints the recipient as trustee of the property, who has legal fiduciary duties to keep or use the property for the benefit of the beneficiary. Winickoff \& Winickoff suggest that in genetic biobanking the general public acts as the beneficiary of the charitable trust. ${ }^{5}$

\section{Figure 1 - The Charitable Trust Model}

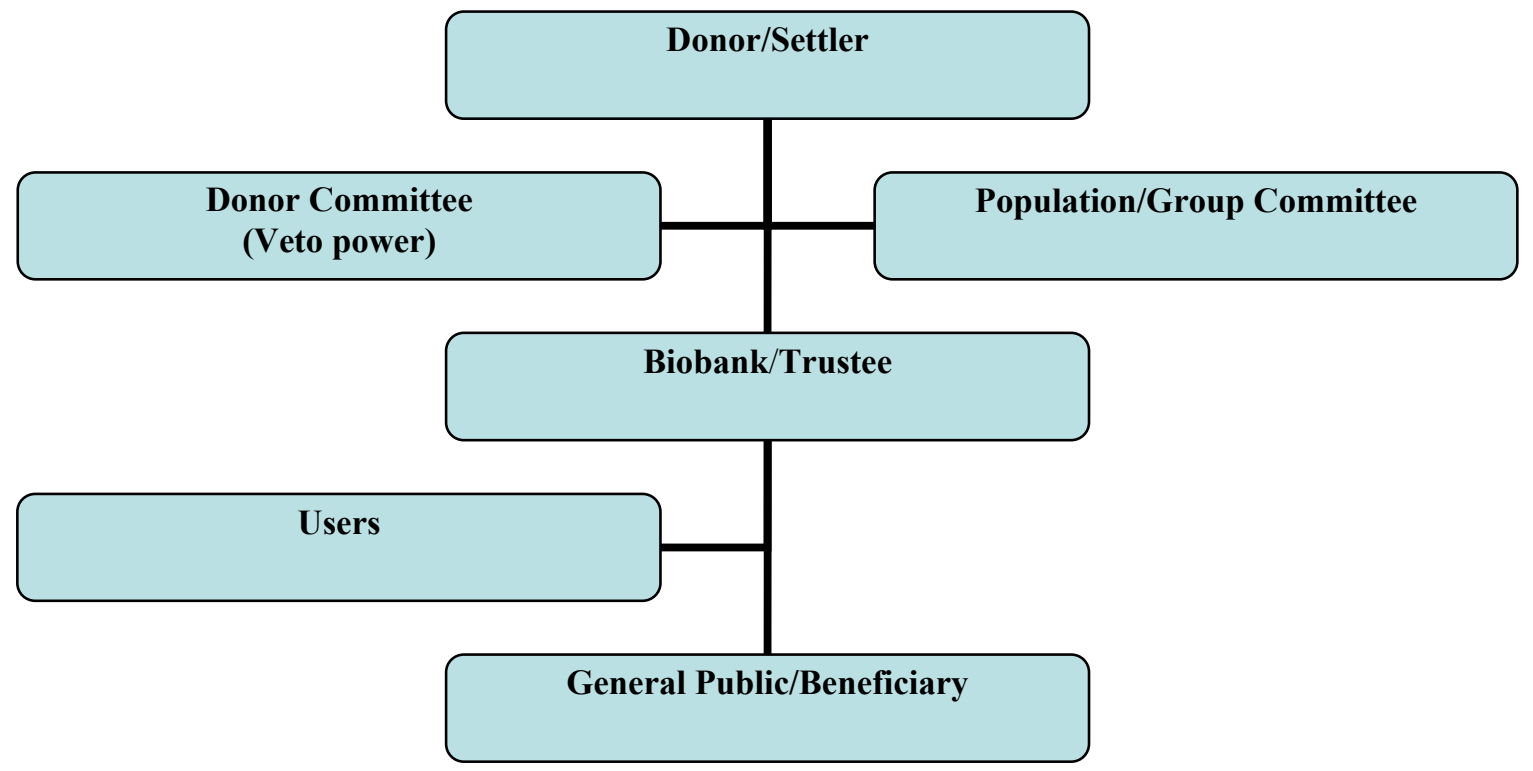


To provide a more viable arrangement, the authors add a few features to the model. First, the trust shall collect samples only if each donor gives "permission" to collect and store the sample. The authors are thus avoiding the traps of the informed consent terminology by using the terminology that was first proposed by Henry Greely. In fact, talking about informed consent would be inappropriate in genomic biobanking, Professor Greely argues. When dealing with large collections of biological samples, participants are not asked to consent to a particular research protocol with specific risks and benefits. In fact, all the uses that investigators will make of the samples are often not foreseeable at the time of the collection. Their samples are therefore more likely becoming part of a research resource, usable for many different protocols, concerning many different medical conditions. "Without knowing what research will be done, one can only speculate on the risks and benefits. For this reason, it might be better in this context to talk about 'permission' for research uses of patient data."6

Second, an institutional review board (IRB) shall approve any subsequent research. Therefore, although the donors have given permission to an open list of researchers, the collected samples can only by used in new research if the IRB approves it. Third, participants should be granted an absolute right of withdrawal. Whenever settlers/donors are no longer interested in being part of the biobank, they should be able to withdraw their permission, and to prevent the biobank from using the samples in future research studies. Furthermore, permission for future research projects would not be required providing that participants are periodically updated on the different protocols that have been approved, and that they retain a right of opting-out whenever dissatisfied with the medical research that is carried out. Finally, Winickoff \& Winickoff envisage other features as essential components of a biobank: the full disclosure of commercial arrangements and the protection of the participants' confidentiality by encrypting all identifying information.

Winickoff \& Winickoff argue that the charitable trust presents three clear advantages, namely the protection of the participants' rights, the propensity to build participants' trust, and the protection and maximization of the scientific value of the biological collection. I shall briefly discuss these arguments. First, the charitable trust protects the rights of the participants in at least two ways: a) the trusted collection shall serve exclusively the interests of the beneficiary - the "general public" -, and the participants are within the general public; b) by having a donors committee and a group or population committee, the interests of the participants are directly taken into consideration in managing the collection. Second, by not being geared toward the maximization of profits but rather toward the maximization of the utility for the beneficiary of the trust, the charitable trust engages in a trust-building relationship with the potential participants. Third, by serving the "general public," the scientific value of the collected samples is maximized. On the other hand, a commercial biobank might have an interest in restricting the access to samples by other research groups. 


\section{$3 \quad$ Assessing the charitable trust model}

In assessing the advantages and disadvantages of the charitable trust model, I shall begin by outlining the advantages that, in my opinion, the model presents. I will then discuss my perplexities of the Winickoff \& Winickoff's proposal.

\subsection{Three advantages of the charitable trust model}

The charitable trust model presents at least three advantages if compared to a model based purely on contractual relationships. First, the charitable trust model favors the separation between control and use of the collected samples. Large collections of human tissue are often being developed as resources that enable future research projects rather than as tools to enhance pre-existing genetic investigations. Therefore, who stores samples and data is often not the user of the same because he/she is not carrying out genetic research directly. In other words, in the real world storage of material and use of the same are often separate, and having an institutional framework - such as the charitable trust model - that builds upon this distinction is a clear advantage.

This dichotomy also (1) reduces the possibilities of conflict of interest between having custody of samples and using them especially in making prioritization decisions, (2) enhances the possibility to perform ethics review of the genetic research, and (3) favors the participation of different interest groups in deciding the fate of stored tissue. First, who manages a collection of human material in the public interest faces prioritization decisions regarding the use of the samples-who should access the database? For what purposes? In which country? Under which conditions? Therefore, if the manager of the collection is himself/herself one of the potential users of the material, he/she faces a constant conflict of interest in making decisions about the use of the collection. In fact, he/she may be inclined to favor a project where he/she has a personal stake over one where he/she has no bearing, without focusing exclusively on the public interest - that's human nature. By having an institutional framework based on the separation between storage and use, the conflict of interest in making prioritization decisions would certainly be reduced.

First, as a practical matter, transparency and opportunity for ethics review are enhanced if storage and use are separate. In this scenario, third-party researchers interested in accessing the samples would always be required to file a request to access the samples - or the genetic data that are derived from the samples. By filing such requests, external researchers would make explicit the circumstances and the intended purpose of their access. This practice would certainly favor a transparent access to databases and accountability of the both the third parties towards the trustees and of the trustees towards the "general public."

Second, the charitable trust model provides a governance framework that facilitates the participation of donor groups in the management of the database. In fact, procedural mechanisms are built in the model so that one or more committees that represent the donor group, or other groups that have an interest in the management of the database, must be established. In the end, this requirement favors participation in the management of the biobank, its transparency, and eventually societal trust. 
Third, the charitable trust model facilitates balancing the different interests that are affected in large-scale DNA collections. The trusted biological samples can only by used to serve the interest of the beneficiary. Thus, each request for access shall be balanced against the interest of the "general public". However, the "general public" can be construed as a complex entity. As the French Comite Consultatif National d'Ethique pour les sciences de la vie et de la santé points out, the "curator [of a database] is at the center of a network of rights and obligations that need to be managed."7 It is certainly wider than the totality of the participants and it probably includes all the different communities that are affected by the genetic research that is conducted by using the database. However, the charitable trust presents the advantage of establishing a procedural mechanism that mediates between the different interests that come into play in genetic research.

\subsection{Unresolved issues}

If the charitable trust model provides the advantages described in the paragraph above, it also fails to solve many controversial issues that biobank raise and its implementation may be practically problematic. In particular, the charitable trust model fails to address controversial issues relating to the ownership of the genetic database and its data and its samples, the right of withdrawal, third-party access, and funding. In the remains of the paper, I illustrate my critique of the model by analyzing issues from these four controversial areas. The conclusion I draw from my analysis is that, although the charitable trust provides an interesting governance model, many of the controversial issues are left open and can only be resolved at the level of the rules that are governing the trust.

\subsubsection{Ownership of samples}

The charitable trust model fails to fully address the ownership issue that genetic databases raise. In today's debate, thinking of a database in terms of ownership is inescapable. In fact, policymakers and courts have thoroughly discussed the donation of human body parts from a property perspective. The charitable trust model partially addresses the issues, because - as ordinarily happen with trusts - the ownership of the samples goes to the trustee. In fact, under the trust agreement, participants formally express their wish to transfer his or her interest in the tissue to the trust. However, many important questions concerning the ownership of the tissue samples, the derived data, and the database in itself are unanswered.

First of all, Winickoff \& Winickoff's model assigns the samples' property to the trust, thus contemplating that owning human material is legally admissible. However, the ethical admissibility of property in the body is controversial. Moreover, from a legal standpoint, "[b]oth the common law and the views of many developing countries" people agree that there is no such thing as property in the body." 8 As a consequence, the charitable trust model might not be compatible with many legal systems to the extent that it requires a formal recognition of property in the body. Alternatively, in order to avoid the intricate question of whether donated tissue becomes the property of the recipient or the participant in biomedical research, commentators and policymakers have proposed the less drastic arrangement of "custodianship" or "stewardship." For instance, the 2005 Draft of the UK BioBank "Policy and Intellectual Property and Access" provides that "UK Biobank Limited [is] the steward 
of [samples and data]". 9 On the other hand, even this second model leaves open many important questions that are intimately connected with the storage and use of human tissue. In fact, being the steward or the custodian of samples assigns you the right to court of law to seek the restitution of stolen samples or the right to pass them out under certain circumstances - all "traditional incidents of property." ${ }^{10}$ In the end, the question that first needs to be addressed is whether a formal recognition of property in the body is the best way to reason about collections of human tissue. To put it in Alexandra George's words: When dealing with banking of human tissues, "[i]s 'property' necessary?"11

The model based on ownership to the trust is also in conflict with those policies that provide that the donation of a tissue sample does not transfer its property to the recipient. Thus the Icelandic Act on Biobanks explicitly provides that the biobanker is not to be considered the owner of the biological samples that are donated to the bank. $^{12}$ Moreover, the non-binding WHO Regional Office report on genetic databases provides that participants in biomedical research should have the "primary control [of] samples or the information generated from them", and that their legal interest "is akin to a property right" (emphasis added). ${ }^{13}$

\subsubsection{Right of withdrawal: How to implement it?}

The controversial aspects of property and biobanks do not end by qualifying the biobanker as trustee of the donated samples. Although the trust as proposed by Winickoff \& Winickoff becomes formally the owner of the donated tissue, the availability of the right of withdrawal challenges the notion that donors are giving up their property interests in the sample. Winickoff $\&$ Winickoff propose that donors shall have an "absolute right" to withdraw the permission to use the samples. ${ }^{14}$ First of all, Winickoff \& Winickoff seems to propose a form of revocable trust - a trust that may be changed or cancelled by its settler/donor or by another person - with an unusual twist: the settler/donor is also a member of the beneficiary group (the public). However, technically it is not a "revocable" trust because, in this case, the withdrawal of biological material of a single settler/donor does not revoke the whole trust. This ambiguity, which derives from the double hat of grantors and beneficiaries that donors wear, may in fact create conflicts between the interest of the participant as a donor and the interest of the participant as a beneficiary. In fact, if a participant exercises his/her right of withdrawal, the charitable trust has to comply even if the withdrawal is against the "interest of the general public"-the genetic make-up of the withdrawing participant could be unusually interesting to researchers. As a consequence, Winickoff \& Winickoff's model leaves open several questions: may the trustee refuse to comply with the request for withdrawal if against the interest of the beneficiaries, thus including the withdrawing participant in the category? What if, after the participant dies, the request comes from a participants' family member or his/her legal representative? Therefore, the property-based model, in which the general public acts as the beneficiary, is somehow in contrast with the idea of granting an absolute right of withdrawal to participants. 
Second, the model does not address the issue of what is the best mechanism to implement the withdrawal of samples and data. The policy options offered by the available policies are several: withdrawal could substantiate in returning samples to the participants, in destroying the samples, in destroying the link between the identity of the donor and the sample (anonymization), in removing the identifying information from the database, in destroying the genetic data derived from the sample, or in "no longer" using them. ${ }^{15}$ However, the charitable trust in itself cannot answer the question of which mechanism is ethically permissible and better protects the interest of both genetic research and research participants.

\subsubsection{Access}

Winickoff \& Winickoff propose the charitable trust model as sharing information and favoring an open-access model. ${ }^{16}$ Indeed, wide access is arguably the best avenue to realize the potentialities of a genetic database. However, the charitable trust model in itself does not answer some questions that access implies. First, the framework does not address the issue of whether external research groups may access the samples-by having the samples shipped to their labs - or simply the genetic data that have been derived by processing the samples. Second, the charitable trust does not answer the question of who may access the samples and whether the public interest that the trust serves implies some prioritization mechanism. Winickoff \& Winickoff suggest that commercial companies may have access to the database. ${ }^{17}$ However, the model does not solve the problem of whether commercial entities that access the databases become owners of the data that are derived from the access, or even may retain (and own) the specimen to whom the trust has granted access. Furthermore, the charitable trust model fails to address the issue of whether donors, health care providers and family doctors may access the database. Shall participants be only given information about the aggregate results of genetic research undertaken using the donated samples or shall they be individually informed if the research findings affect their future care? Finally the model does not solve the issue of whether external researchers and private corporations may access sensitive data that have been collected along with the samples.

Arguably, if broad access is granted, benefits for the "general public" will be greater. However, the notion of "general public" as beneficiary is too vague to provide practical guidelines without further specifications. One can argue that providing genetic counselling to the participants is serving the "general public." At the same time, one can argue that granting exclusive access to one pharmaceutical company is the best way to serve the "general public." In the end, the trustees will be asked to make these sorts of judgements in adopting the policies that regulate third-party access. Most of the answers will only lie in those rules governing the biobank and its contractual relations with external actors rather than in the governance framework.

The 2005 Draft of the UK BioBank "Policy and Intellectual Property and Access" provides a clear illustration that a governance framework in itself does not address the most pressing issues that biobanking activities raise. ${ }^{18}$ In fact, although the UK BioBank has a well-defined governance structure based on the principles of stewardship of the samples, open-access of data and serving the public interest, the overall framework leaves unresolved many issues that must be addressed by specific rules. In particular, the 2005 Draft regulates a wide variety of issues such as 
intellectual property rights, the access to human material and data, the re-contacting of participants, the terms of access, and the dissemination of research results.

Finally, Winickoff \& Winickoff argue that the charitable trust model is the best way to ensure that the scientific value of the collected samples is maximized. ${ }^{19}$ It follows that commercial entities would be less willing to maximize the potentialities of the samples, if in charge of the same collection. With its governance structure, the charitable trust model is arguably able to retain the sort of identifiers that are usually stripped in the commercial context-in fact, at least the United States, commercial companies have tighter restraints that non-profit entities performing medical research. $^{20}$ Therefore, maintaining the longitudinal and epidemiological component of the genomics cohort study would be enabled and facilitated, which would consequently lead to maximizing the "scientific value" of the collection. However, one could argue that accountability to the shareholders provides stronger incentives to the managing board than accountability to the "general public" and that corporate law requires the disclosure of enough information to ensure public oversight of the operations of the company. Because of the differences in the legal regimes of commercial companies and of non-profit companies, one can argue that the charitable trust model is superior. However, this argument opens the door for debating whether the legal disadvantages of commercial corporations are reasonable. Also, the argument is based on an empirical claim that ought to be demonstrated before accounting maximization of scientific value among the benefits of the charitable trust model. In my opinion, the empirical claim ought to be demonstrated and the policy merits of different regimes for different actors ought to debated before accounting maximization of scientific value among the benefits of the charitable trust model.

\subsubsection{Funding}

The key benefit of the charitable trust is that the collection serves the "general public." An ideal corollary to this premise is that public money entirely funds the trust. However, a charitable trust is likely to need some private funding to reach its goals. It follows that charitable trusts are likely to transact with per-profit companies, for instance by paying a fee-based access. In a stronger scenario, charitable trusts would also have to form partnerships with per-profit companies that operate in the market. At least that is what Winickoff \& Winickoff envision: "biotechnology and pharmaceutical companies that want tissue bank or data . . could be partners with the tissue bank in order to help fund it." ${ }^{21}$ However, in the end, the Winickoff \& Winickoff model insufficiently details how it could balance openness and publicbenefit with commercial collaboration.

\section{Conclusions}

The charitable trust model provides an interesting governance model that is fertile of practical applications. It certainly offers a procedural mechanism to mediate the different interests that come into play, and to balance them. However, many of the issues can only be solved at level of rules that govern the trust - or more generally any biobank, whether public or private. Thus the charitable trust model does not fully solve issues of ownership of the samples - especially if combined with an absolute right of withdrawal — of access to the samples and the data, and of the residual role of 
commercial entities in population genetics. Further theoretical and empirical analysis of the permissible actions that biobankers can take with regard to the collections that they manage is needed to develop the intellectual capacity that is necessary to cope with the pressing challenges of genetic databases.

\footnotetext{
*An earlier version of this paper was presented at the PropEur Workshop "Benefit Sharing and Charitable Trust as Models of Regulation in IPR" (8-9 July 2004 Cardiff, UK). I thank all participants to the Workshop, the referees and Sue Burrows for the helpful comments. This article has benefited from the author's work as a member of a research collaboration "Human Genetic Databases: Towards a Global Ethical Framework" involving the Institute of Bioethics at the University of Geneva, the Institute for Medical Ethics of the Charité, Berlin, and the Department of Ethics, Trade, Human Rights, and Health Law, WHO, Geneva, and funded by "Réseau universitaire international de GenèveGeneva International Academic Network" (RUIG-GIAN) and in particular from conversations on the topic with Nikola Biller-Andorno, Bernice Elger, Alex Capron, and Alexandre Mauron.
}

${ }^{1}$ The Advisory Committee on Health Research. 2002. Genomics and World Health. Geneva. World Health Organization: 26 and 114.

${ }^{2}$ Id., p.114.

${ }^{3}$ D. E. Winickoff, \& R. N. Winickoff. The Charitable trust as a Model for Genomic Biobanks. NEJM 2003; 349: 1180-1184.

${ }_{5}^{4}$ Id., p. 1182.

${ }^{5}$ Ibid.

${ }^{6}$ H. T. Greely. Breaking the Stalemate: A Prospective Regulatory Framework for Unforeseen Research Uses of Human Tissue Samples and Health Information", Wake Forest Law Review 1999; 34: 737

${ }^{7}$ Comité Consultatif National d'Éthique pour les sciences de la vie et de la santé. 2003. Problèmes éthiques posés par les collections de matériel biologique et les données d'information associées: "biobanques", "biothèques". Avis n. 77- 20 March 2003. Available at <http://www.ccneethique.fr/francais/avis/a_077.htm>.

8 D. Dickerson. Consent, Commodification and Benefit-Sharing in Genetic Research. Developing World Bioethics, 2004; 4(2): 121. However in some jurisdictions the issue of the legal admissibility of property in the body is far from being clear. See the often cited California Supreme Court case of Moore v. Regents of the University of California, 793 P.2d 479 (Cal. 1990), which illustrates the difficulty in recognizing property rights to donors of human tissue.

${ }^{9}$ UK BIOBANK. Policy on Intellectual Property ("IP") and Access, at 2.1. Available at

$<$ www.ukbiobank.ac.uk/docs/UKBiobankIPandAccesspolicyfirstpublicdraft11.1.5final2.pdf> (Draft, 11 January 2005).

${ }^{10}$ D. Winickoff, Governing Population Genomics: Law, Bioethics, and Biopolitics in Three Case Studies, Jurimetrics 2003, 43: 206.

${ }^{11}$ A. George, Is 'property' necessary? On owning the human body and its parts, Res Publica 2004; 10: $15-42$.

${ }^{12}$ Iceland, Act on Biobanks n. 100/2000, Art. 10 (Passed on 13. May 2000).

${ }^{13}$ World Health Organization Regional Office for Europe. 2001. Genetic Databases: Assessing the benefits and the impact on human \& patient rights. Report for Consultation. Geneva. World Health Organization: 8.

${ }^{14}$ Winickoff, \& Winickoff, op. cit. note 3, p. 1182.

${ }^{15}$ UNESCO. 2003. "International Declaration on Human Genetic Data. Paris: UNESCO: Art. 9(b).

Available at $<$ http://portal.unesco.org/en/ev.php-

URL ID $=17720 \& U R L D O=D O$ TOPIC\&URL SECTION=201.html $>$.

${ }^{16}$ Winickoff, \& Winickoff, op. cit. note 3, p. 1183.

${ }^{17} \mathrm{Ibid}$

${ }^{18}$ UK BIOBANK. Policy on Intellectual Property ("IP") and Access. Available at

$<$ www.ukbiobank.ac.uk/docs/ UKBiobankIPandAccesspolicyfirstpublicdraft11.1.5final2.pdf> (Draft, 11 January 2005).

${ }^{19}$ Winickoff, \& Winickoff, op. cit. note 3, p. 1182

${ }^{20} \mathrm{I}$ am indebted for this point to one of the anonymous referees, whose words are almost entirely reflected in the last two sentences.

${ }^{21}$ Id., p. 1183 . 